\title{
Reasons for choosing dentistry as a career among dental students in Saudi Arabia
}

\author{
Khaled Rateb Al-Hallak ${ }^{1}$, Mohammad Zakaria Nassani ${ }^{1}$, Mohammed Moustafa Heskul ${ }^{2}$, \\ Mazen Deib Doumani², Mahmoud Darwish ${ }^{1,3}$
}

Correspondence: Dr. Mohammad Zakaria Nassani Email: mznassani@hotmail.com

\begin{abstract}
'Department of Prosthetic Dental Sciences, AlFarabi College for Dentistry and Nursing, Riyadh, Saudi Arabia,

${ }^{2}$ Department of Restorative Dental Sciences, AlFarabi College for Dentistry and Nursing, Riyadh, Saudi Arabia,

${ }^{3}$ Department of Prosthodontics, Faculty of Dentistry, Suez Canal University, Ismailia, Egypt
\end{abstract}

\section{ABSTRACT}

Objective: This study aimed to identify reasons and influential factors for choosing dentistry as a career among dental students in Saudi Arabia. The preferred field of dental specialty following graduation will also be investigated. Materials and Methods: A questionnaire was developed and circulated among undergraduate dental students studying at a private dental college in Saudi Arabia. A list of 16 reasons that possibly influenced students' decision to study dentistry was presented and participants were invited to indicate on a 5-point Likert scale the extent each reason influenced their choice of dentistry as a career. The listed reasons were categorized into economic, professional, vocational, social and personal reasons. Results: Totally, 788 out of 970 questionnaires were completed (response rate: 81\%). Proportion of female students exceeded proportion of male students (59\% and $41 \%$, respectively) and most participants were Saudi students $(73 \%)$. The top three influential factors on students' decision to study dentistry were "Dentistry is a prestigious profession," "I like to treat people and improve their appearance," and "I like working with people and caring for them." Variations were identified between male and female students and also between Saudi and non-Saudi students in the reasons to choose dentistry as a career. The vast majority of participants $(94 \%)$ expressed a desire to follow a postgraduate study. Orthodontics and oral surgery were the most preferred dental specialties. Conclusion: The social and vocational reasons were the main factors that motivated this group of dental students to attend a dental program. Greater training opportunities should be planned to accommodate the speculated increasing demand for postgraduate dental education in Saudi Arabia.

Key words: Career, dental students, dentistry, Saudi Arabia

\section{INTRODUCTION}

The choice of dentistry as a career for sons and daughters sounds appealing for many families in the Arabic world..$^{[1]}$ It is also a dream for some of the Arab youth to become a dentist. ${ }^{[2]}$ This can be mainly attributed to cultural, social, and economic factors. ${ }^{[3]}$

\begin{tabular}{|l|l|}
\hline \multicolumn{3}{|c|}{ Access this article online } \\
\hline Quick Response Code: \\
\hline
\end{tabular}

The image of a dentist in minds of Arabic people is associated with wealth and prestige. ${ }^{[4]}$ As well, being a dentist is a sign of success and excellence. ${ }^{[5]}$ Such attractive charisma for the dentist among the Arabic people increased the demand on dentistry as a career

This is an open access journal, and articles are distributed under the terms of the Creative Commons Attribution-NonCommercial-ShareAlike 4.0 License, which allows others to remix, tweak, and build upon the work non-commercially, as long as appropriate credit is given and the new creations are licensed under the identical terms.

For reprints contact: reprints@medknow.com

How to cite this article: Al-Hallak KR, Nassani MZ, Heskul MM, Doumani MD, Darwish M. Reasons for choosing dentistry as a career among dental students in Saudi Arabia. Eur J Dent 2018;12:275-80.

DOI: 10.4103/ejd.ejd_335_17 
in the Arabic community. ${ }^{[1]}$ In response to that and over the past few years, there has been an expansion in the delivery of dental programs in many Arabic countries. ${ }^{[1,6]}$ In Saudi Arabia, 26 dental programs were available in the governmental and private sectors by the beginning of the academic year 2016-2017. Such huge number of dental programs in a country that its population is about thirty-one millions is an indicator of the importance given to dental education in the Saudi community ${ }^{[7-9]}$ However, from strategic planning point of view, the increased delivery of dental programs would probably lead to inflation in the number of dental graduates. This, in turn, would have its implications on the job market and perhaps quality of dental practice in Saudi Arabia. At such critical moment, decision-makers and policy-planners in higher education need to address this issue. Investigation of factors that are behind the tendency to choose dentistry as a career among a large number of students in Saudi Arabia may be a starting point to rearrange the educational priorities in the country. ${ }^{[10]}$ Furthermore, a review and revaluation of the current policies and trends in the delivery of dental education can be made in the light of such investigation. ${ }^{[11,12]}$ Effective management of future dental workforce in Saudi Arabia would also require thorough understanding of students' motivation for the choice of dentistry as a profession. Moreover, as part of comprehensive planning for dental education in Saudi Arabia, there is a need to assess the intent of Saudi dental students to advance in their dental education and attend postgraduate programs. The aim of this study was to identify reasons and influential factors for choosing dentistry as a career among dental students in Saudi Arabia. The preferred field of dental specialty after graduation will also be investigated.

\section{MATERIALS AND METHODS}

\section{Setting and sample}

This study was conducted at AlFarabi College for Dentistry and Nursing. This is a big private college located in east of Riyadh, Saudi Arabia. The target population was undergraduate students studying dentistry in the academic year 2015-2016 ( No = 1483). As there was no specific outcome target, the sample size was calculated based on the assumption that the expected maximum frequency of the outcome factor is $50 \%$. Using version 3.01 of OpenEpi software for epidemiologic statistics (Bill and Melinda Gates Foundation, Emory University, Atlanta, Georgia, USA) ${ }^{[13]}$ the required sample size for $99 \%$ confidence level was 664 dental students. However, to achieve the target sample size and taking into account the risk of declining participation, the questionnaire was distributed among 970 students over the course of study. Of these, 788 questionnaires were completed resulting in $81 \%$ response rate.

\section{Instrument}

This study is a cross-sectional descriptive study. The research instrument was a self-administered questionnaire that was developed based on similar previous investigations. ${ }^{[2-4]}$ The questionnaire was presented in Arabic and was first piloted among a group of twenty students to ensure validity and clarity of contents (ten male and ten female students). This led to minor modifications in questions' format and sequence. Afterward, the reliability of the questionnaire was assessed by inviting another group of ten students to complete the questionnaire in two occasions with a 1-week interval. The reliability analysis illustrated that the values of Cronbach's alpha test for questionnaire items ranged between 1 and 0.75 indicating a high level of internal consistency for questionnaire items.

Questionnaire contents were grouped into three sections. In the first section, the student was asked to record his/her gender, age, nationality, current year of study, and parents' level of education. The student was also requested to clarify whether studying dentistry was his/her first study choice or not.

In the second section of the questionnaire, a list of 16 reasons that possibly influenced students' decision to study dentistry was presented and participants were required to indicate on a 5-point Likert scale the extent each reason influenced their choice of dentistry as a career [Table 1]. The two extremes of Likert scale were as follows: 1 - strongly disagree and 5 - strongly agree. To facilitate analysis, the listed reasons were categorized into economic, professional, vocational, social, and personal reasons [Table 1].

In the last part of the questionnaire, participating students were instructed to select from a list their preferred field of dental specialty after graduation. An option of no preference for any specialty was also listed.

\section{Ethical considerations and data collection}

This survey was carried out over the academic year 2015-2016. The study protocol was registered and approved by the Research Ethics Committee at AlFarabi College for Dentistry and Nursing, Riyadh, Saudi Arabia. Student Affair Unit at AlFarabi was 
Al-Hallak, et al.: Choosing dentistry as a career among dental students

\begin{tabular}{|c|c|c|c|c|c|}
\hline Reasons affecting choice of dentistry & $\begin{array}{c}\text { Strongly } \\
\text { agree }(n=5) \\
n(\%)\end{array}$ & $\begin{array}{l}\text { Agree }(n=4) \\
n(\%)\end{array}$ & $\begin{array}{l}\text { Neutral }(n=3) \\
\quad n(\%)\end{array}$ & $\begin{array}{l}\text { Disagree }(n=2) \\
n(\%)\end{array}$ & $\begin{array}{c}\text { Strongly } \\
\text { disagree }(n=1), \\
n(\%)\end{array}$ \\
\hline \multicolumn{6}{|l|}{ Economic reasons } \\
\hline Easy to find jobs & $230(29.2)$ & $198(25.1)$ & $258(32.7)$ & $64(8.1)$ & $38(4.8)$ \\
\hline Payment is better & $206(26.1)$ & $290(36.8)$ & $208(26.4)$ & $44(5.6)$ & $40(5.1)$ \\
\hline \multicolumn{6}{|l|}{ Professional reasons } \\
\hline $\begin{array}{l}\text { I can practice dentistry independently following } \\
\text { graduation without a need to be a specialist }\end{array}$ & $196(24.9)$ & $260(33)$ & $222(28.2)$ & $72(9.1)$ & $38(4.8)$ \\
\hline I can be my own boss & $282(35.8)$ & $258(32.7)$ & $196(24.9)$ & $32(4.1)$ & $20(2.5)$ \\
\hline $\begin{array}{l}\text { Dentistry has more regular work hours } \\
\text { than other medical professions }\end{array}$ & $326(41.4)$ & $236(29.9)$ & $156(19.8)$ & $58(7.4)$ & $12(1.5)$ \\
\hline Dentists usually do not deal with life threat cases & $216(27.4)$ & $208(26.4)$ & $254(32.2)$ & $52(6.6)$ & $58(7.4)$ \\
\hline \multicolumn{6}{|l|}{ Vocational reasons } \\
\hline $\begin{array}{l}\text { I like to treat people and improve } \\
\text { their appearance }\end{array}$ & $434(55.1)$ & $230(29.2)$ & $80(10.2)$ & $22(2.8)$ & $22(2.8)$ \\
\hline $\begin{array}{l}\text { Dentistry will give me the opportunity } \\
\text { to work with my hands }\end{array}$ & $340(43.1)$ & $290(36.8)$ & $126(16)$ & $20(2.5)$ & $12(1.5)$ \\
\hline Dentistry suits my artistic talent & $272(34.5)$ & $278(35.3)$ & $164(20.8)$ & $52(6.6)$ & $22(2.8)$ \\
\hline I like working with people and caring for them & $368(46.7)$ & $284(36)$ & $96(12.2)$ & $28(3.6)$ & $12(1.5)$ \\
\hline \multicolumn{6}{|l|}{ Social reasons } \\
\hline $\begin{array}{l}\text { One of my relatives or friends is a dentist } \\
\text { and encouraged me to study dentistry }\end{array}$ & $180(22.8)$ & $172(21.8)$ & $62(7.9)$ & $100(12.7)$ & $274(34.8)$ \\
\hline I studied dentistry because of my family desire & $136(17.3)$ & $18(22.8)$ & $194(24.6)$ & $108(13.7)$ & $170(21.6)$ \\
\hline Dentistry is a prestigious profession & $524(66.5)$ & $186(23.6)$ & $62(7.9)$ & $14(1.8)$ & $2(0.3)$ \\
\hline \multicolumn{6}{|l|}{ Personal reasons } \\
\hline $\begin{array}{l}\text { My school GPA qualified me to } \\
\text { choose dentistry as a career }\end{array}$ & $256(32.5)$ & $296(37.6)$ & $138(17.5)$ & $60(7.6)$ & $38(4.8)$ \\
\hline I got a scholarship to study dentistry & $178(22.6)$ & $140(17.8)$ & $92(11.7)$ & $116(14.7)$ & $262(33.2)$ \\
\hline I previously worked in fields related to dentistry & $108(13.7)$ & $126(16)$ & $150(19)$ & $156(19.8)$ & $248(31.5)$ \\
\hline
\end{tabular}

contacted to provide the authors with study schedules of dental students. Afterward, a plan was made in coordination with college administration to circulate study questionnaire among male and female dental students from all study levels during regularly scheduled class sessions. Students were briefed by the first author on the aim of study and invited to participate. The average time for completing the questionnaire was $10 \mathrm{~min}$. Students were assured confidentiality of information they would provide and that participation is anonymous and voluntary.

\section{Data analysis}

The SPSS statistical package was used for data analysis (IBM SPSS Statistics for Windows, Version 20.0, Released 2011, IBM Corp, Armonk, New York, USA). Descriptive statistics presented sociodemographic data of participants, and frequency table was generated to illustrate response of students to questionnaire items. The nonparametric Mann-Whitney U-test was used to identify any differences among students' groups in their reasons for choosing dentistry as a career. The significance level was set at $P<0.05$.

\section{RESULTS}

Totally, 788 questionnaires were completed. The mean age of respondents was 22 years (standard deviation $=1.9$ ) with a range between 19 and 30 years. Table 2 shows that participation comprised students from all study levels. Number of female students exceeded number of male students and most participants were Saudi $(73 \%)$. Countries of non-Saudi students were Syria, Jordan, Sudan, and Egypt. Although there was a wide variation in parents' education, the majority of students' parents were highly educated [Table 2]. Response of students to the question whether dentistry was their first study choice indicated that this was the case for a majority of them $(61 \%)$.

Table1 illustrates the impact of some reasons on students' choice of dentistry as a career. It can be noted that the top three items were "Dentistry is a prestigious profession," "I like to treat people and improve their appearance," and "I like working with people and caring for them." Participants strongly agreed that these items were highly influential on their decision to study dentistry [Table 1]. 
The statistical comparison between male and female students indicated that the economic and personal reasons had significantly higher impact on male students in their choice of dentistry as a career $(P<0.05)$. On the other hand, the professional and vocational reasons were significantly more influential on female students' decision to study dentistry $(P<0.05)$ [Table 3].

To identify any differences between Saudi and non-Saudi students in their reasons for study of dentistry, the Mann-Whitney U statistical test indicated that the social reasons were significantly more influential among non-Saudi students $(P<0.05)$. For Saudi students, the personal reasons had significantly greater impact on their decision to study dentistry $(P<0.05)$. No significant differences were found between Saudi and non-Saudi students with respect to economic, professional, and vocational reasons for choice of density as a career [Table 4].

Analysis of students' response to the last part of study questionnaire revealed that the vast majority of participants (94\%) expressed a desire to follow a postgraduate study. Among the different dental specialties, a considerable proportion of students expressed their willingness to study orthodontics and oral surgery (30\% and $23 \%$, respectively).

\section{DISCUSSION}

Since 1987, there has been dramatic expansion in dental education in Saudi Arabia. The number of dental schools increased from 3 to 26 and the dentist-to-population ratio decreased from 1:8906 to $1: 2326 \cdot{ }^{[14,15]}$ This, in turn, has increased the pressure on the Saudi government to create wider job opportunities for the escalating number of Saudi dental graduates. In response to that, the Saudi Ministry of Labor in coordination with Saudi Ministry of Health issued a decision on May 2017 to stop recruiting dentists from abroad. This decision will probably mark a big change in the Saudi dental job market as foreigner dentists used to occupy the majority of dental jobs in Saudi Arabia for a long time. It can be stated that publication of this study comes at a turning point since dentistry as a career is currently under close scrutiny of decision-makers and policy-planners in the Arabic Kingdom.

While reasons for choosing dentistry as a career have been investigated in many countries worldwide, ${ }^{[16]}$ such investigations are still limited in the Arabic

\begin{tabular}{lc} 
Table 2: Characteristics of participating \\
students $(\boldsymbol{n = 7 8 8 )}$ \\
\hline Variable \\
\hline Gender \\
Male \\
Female \\
Nationality \\
$\quad$ Saudi & $324(41)$ \\
Non-Saudi & $464(59)$ \\
Year of study & $578(73)$ \\
$1^{\text {st }}$ year & $210(27)$ \\
$2^{\text {nd }}$ year & \\
$3^{\text {rd }}$ year & $92(11.5)$ \\
$4^{\text {th }}$ year & $204(26)$ \\
$5^{\text {th }}$ year & $170(22)$ \\
$6^{\text {th }}$ year & $102(13)$ \\
Parent's education & $128(16)$ \\
Illiterate $^{\text {Elementary school }}$ & $92(11.5)$ \\
Preparatory/secondary school $^{\text {University }}$ & \\
Postgraduate study & $8(1)$ \\
\hline
\end{tabular}

\begin{tabular}{|c|c|c|c|}
\hline $\begin{array}{l}\text { Reasons affecting } \\
\text { choice of dentistry }\end{array}$ & $\begin{array}{c}\text { Male } \\
\text { (mean rank) }\end{array}$ & $\begin{array}{c}\text { Female } \\
\text { (mean rank) }\end{array}$ & $P$ \\
\hline Economic reasons & 427.30 & 371.59 & $0.001^{*}$ \\
\hline Professional reasons & 372.29 & 410.01 & $0.021^{*}$ \\
\hline Vocational reasons & 366.46 & 414.08 & $0.004^{*}$ \\
\hline Social reasons & 409.01 & 394.37 & 0.132 \\
\hline Personal reasons & 420.40 & 376.41 & $0.007^{*}$ \\
\hline
\end{tabular}

*Significant difference at $P<0.05$ as indicated by Mann-Whitney U-test

\begin{tabular}{|c|c|c|c|}
\hline $\begin{array}{l}\text { Reasons affecting } \\
\text { choice of dentistry }\end{array}$ & $\begin{array}{c}\text { Saudi } \\
\text { (mean rank) }\end{array}$ & $\begin{array}{c}\text { Non-Saudi } \\
\text { (mean rank) }\end{array}$ & $P$ \\
\hline Economic reasons & 391.49 & 402.79 & 0.532 \\
\hline Professional reasons & 387.17 & 414.66 & 0.131 \\
\hline Vocational reasons & 388.61 & 410.72 & 0.223 \\
\hline Social reasons & 367.60 & 468.55 & $<0.001^{*}$ \\
\hline Personal reasons & 437.46 & 276.26 & $<0.001^{*}$ \\
\hline
\end{tabular}

*Significant difference at $P<0.05$ as indicated by Mann-Whitney U-test

countries. ${ }^{[2-4,17,18]}$ Review of these studies shows that choice of dentistry as a profession can be influenced by a wide range of factors across countries and populations. Among these, factors are social, financial, professional, vocational, and personal factors. ${ }^{[16,19-22]}$ In this respect, the cultural values and surrounding environment can also be implicated. ${ }^{[11,23,24]}$ 
In Saudi Arabia, only few attempts have been made so far to assess career motivations of dental students..$^{[8,9,14,25]}$ Al-Dlaigan et al. ${ }^{[8,9]}$ and Halawany ${ }^{[25]}$ targeted dental students at King Saud University. The study of Halawany et al. ${ }^{[14]}$ was conducted among students studying at governmental and private dental schools (11 public and 6 private schools). The current study is the first to target a whole sample of dental students studying at a Saudi private dental college. It is well known for Saudi educators that admission criteria for studying dentistry at private universities/colleges in Saudi Arabia are different from that at public ones. In the private sector, less stringent admission criteria are followed. Furthermore, the student has to pay tuition fees or to find a source of fund for his/her study. These factors may affect the nature and profile of dental students enrolled in private universities/colleges. Their reasons to study dentistry may also be different from students enrolled in public universities/colleges. It can be stated that this study complements the earlier similar Saudi studies and could possibly update and add more to our knowledge and understanding of the reasons for studying dentistry in Saudi Arabia.

The sample recruited in this survey is a convenience sample. Nevertheless, it is a large sample that includes both genders with a majority of Saudi students. Furthermore, the fact that almost quarter of the study sample is students who are sons and daughters of residents in Saudi Arabia provides another dimension for this study.

Although the findings of this study are not necessarily generalizable to all dental students in Saudi Arabia, these findings can be a useful guide for decision-makers in the Oral health and dental education sectors in Saudi Arabia for understanding the reasons of Saudi and non-Saudi students to study dentistry.

The results of this survey illustrate that perception of dentistry as a prestigious profession was the main driver for a majority of participating students to study dentistry. The vocational factors played also a significant role in students' decision to choose dentistry as a career. However, the impact of professional and economic factors on this sample of dental students should not be underestimated since they motivated a considerable proportion of them to study dentistry. While the social and vocational factors were the top factors that motivated this group of dental students to attend a dental program at a private institute, the socioeconomic factors were the main reasons for studying dentistry among dental students at King Saud University. ${ }^{[25]}$ Reasons for such finding require further investigation.

The outcome of this research underlines gender difference in the impact of some factors on students' choice of dentistry. This is in line with earlier Saudi studies ${ }^{[14,25]}$ and should be considered when planning dental education in Saudi Arabia. It seems that the economic and personal factors have greater impact on male students' decision to study dentistry whereas female students are more influenced by vocational and professional factors. Further work to explain this gender difference is recommended.

Although there were some differences between Saudi and non-Saudi students in their reasons to study dentistry, the level of agreement between the two groups of dental students is apparently high. The difference pertaining personal and social factors is not surprising as most Saudi students are supported by governmental scholarships while most of non-Saudi students have to be funded by their parents. It seems that surrounding environment and dominant culture play greater role in shaping students' career motivations rather than students' nationality per se.

Restorative and esthetic dentistry was the most favorable specialty for the final-year dental students from 17 universities in Saudi Arabia. This was followed by endodontics and then prosthodontics. ${ }^{[14]}$ In another study among students in King Saud University, the most preferred specialty among male students was oral maxillofacial surgery. However, it was operative dentistry among female students. ${ }^{[25]}$ Moreover, the same author concluded that there will be a future need for postgraduate education in dentistry in Saudi Arabia. In this survey, orthodontics followed by oral surgery were the most favorable dental specialties for the participating students. However, regardless of the preferred field of dental specialty, there was apparent inclination among the vast majority of the surveyed dental students in this study to follow a postgraduate study. This means that more training opportunities and postgraduate programs should be planned to accommodate the speculated increasing demand for postgraduate dental education in Saudi Arabia.

To obtain a full picture about motivations of Saudi students to study dentistry, a future national survey is highly recommended. For more in-depth understanding of the factors affecting the choice of dentistry as a career among dental students in Saudi 
Arabia, a qualitative study is suggested. Further similar research could also target dental students in the Gulf area where comparable cultural, social, and economic factors do exist.

\section{CONCLUSION}

Within the limitations of this study, it can be concluded that reasons for choosing dentistry as a career among the surveyed dental students are mostly related to social and vocational factors. Gender differences in career motivations do exist among this group of students, and in the near future, a high demand for postgraduate dental education in Saudi Arabia is expected.

\section{Acknowledgments}

The authors wish to thank the students of AlFarabi College for Dentistry and Nursing in Riyadh who participated so willingly in this study.

\section{Financial support and sponsorship \\ Nil.}

\section{Conflicts of interest}

There are no conflicts of interest.

\section{REFERENCES}

1. Baqain $\mathrm{ZH}$, Alshalan TA, Naaman N, Faleh S. An overview of dental education in the Arab world. Fac Dent J 2016;7:172-4.

2. Mashlah AM. Dentistry students' reasons for choosing dentistry as a career in Damascus university. East Mediterr Health J 2012;18:508-14.

3. Banabilh SM. Career decisions of undergraduate dental students at the university of science and technology, Yemen. J Dent Educ 2013;77:331-6.

4. Al-Bitar ZB, Sonbol HN, Al-Omari IK. Reasons for choosing dentistry as a career by Arab dental students. Eur J Dent Educ 2008;12:247-51.

5. Gallagher J, Clarke W, Wilson N. Understanding the motivation: A qualitative study of dental students' choice of professional career. Eur J Dent Educ 2008;12:89-98.

6. Gaballah K, Al-Salehi SK. Postgraduate dental training in the United Arab Emirates. Fac Dent J 2013;4:148-51.

7. Ashri NY, Al Ajaji N, Al Mozainy M, Al Sourani R. Career profile of dentists in Saudi Arabia. Saudi Dent J 2009;21:28-36.

8. Al-Dlaigan YH, Al-Sadhan R, Al-Ghamdi M, Al-Shahrani A, Al-Shahrani M. Postgraduate specialties interest, career choices and qualifications earned by male dentists graduated from King Saud university. Saudi Dent J 2011;23:81-6.

9. Al-Dlaigan YH, Albarakati SF, Al-Habeeb F, Al-Hulaily M. Career characteristics and postgraduate education of female dentist graduates of the college of dentistry at King Saud University, Saudi Arabia. Saudi Dent J 2012;24:29-34.

10. Abbott BJ, Wege WR, Volkmann KR, Forde EB. Dental student recruitment. J Dent Educ 1984;48:645-8.

11. Tanalp J, Ilguy D, Dikbas I, Oktay I. Demographic profile and future expectations of students enrolled in a Turkish private dental school. J Dent Educ 2012;76:800-9.

12. Aggarwal A, Mehta S, Gupta D, Sheikh S, Pallagatti S, Singh R, et al. Dental students' motivations and perceptions of dental professional career in India. J Dent Educ 2012;76:1532-9.

13. Dean AG, Sullivan KM, Soe MM. OpenEpi: Open Source Epidemiologic Statistics for Public Health, Version 3.01. Available from: http://www. OpenEpi.com. [Last updated on 2013 Apr 06; Last accessed on 2018 Feb 12]

14. Halawany HS, Binassfour AS, AlHassan WK, Alhejaily RA, Al Maflehi N, Jacob V, et al. Dental specialty, career preferences and their influencing factors among final year dental students in Saudi Arabia. Saudi Dent J 2017;29:15-23.

15. Saudi Ministry of Health: Health Statistics; 2015-2016. Available from: http://www.moh.gov.sa/en/Ministry/Statistics/Pages/default. aspx. [Last accessed on 2017 Jun 18].

16. Du Toit J, Jain S, Montalli V, Govender U. Dental students' motivations for their career choice: An international investigative report. J Dent Educ 2014;78:605-13.

17. Maatouk F, El-May W, Ghedira H, Fathallah N. Profile of first year dental students in tunisia. East Mediterr Health J 2001;7:52-9.

18. Rashid H, Manoharan A, Abufanas S, Gallagher JE. Motivation for a career in dentistry: The views of dental students in the United Arab Emirates. Int Dent J 2013;63:259-65.

19. Lalloo R, Ayo-Yusuf OA, Yengopal V. Early-phase dental students' motivations and expectations concerning the study and profession of dentistry. SADJ 2008;63:216-20.

20. Baharvand M, Moghaddam EJ, Pouretemad H, Alavi K. Attitudes of Iranian dental students toward their future careers: An exploratory study. J Dent Educ 2011;75:1489-95.

21. Freire Mdo C, Jordao LM, de Paula Ferreira N, de Fatima Nunes M, Queiroz MG, Leles CR, et al. Motivation towards career choice of Brazilian freshman students in a fifteen-year period. J Dent Educ 2011;75:115-21.

22. dos Santos BF, Nicolau B, Muller K, Bedos C, Zuanon AC. Brazilian dental students' intentions and motivations towards their professional career. J Dent Educ 2013;77:337-44.

23. Karibe H, Kawakami T, Suzuki A, Warita S, Ogata K, Aoyagi K, et al. Career choice and attitudes towards dental education amongst dental students in Japan and Sweden. Eur J Dent Educ 2009;13:80-6.

24. Patel D, Saiyed MH. Factors for choosing dentistry as a career: A study of first-year dental students, India. J Int Oral Health 2009;1:10-9.

25. Halawany HS. Career motivations, perceptions of the future of dentistry and preferred dental specialties among Saudi dental students. Open Dent J 2014;8:129-35. 